Provided for non-commercial research and education use. Not for reproduction, distribution or commercial use.

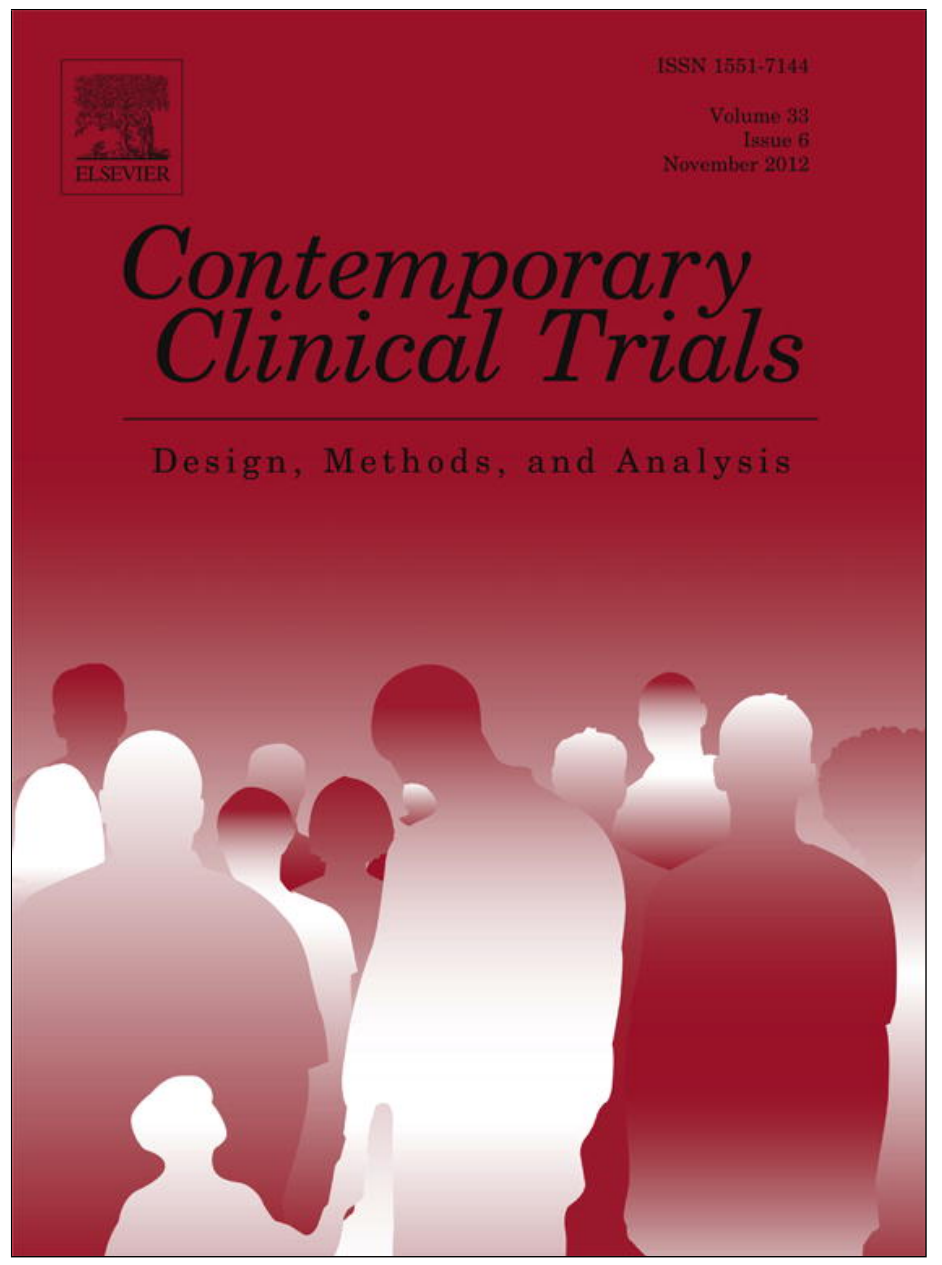

This article appeared in a journal published by Elsevier. The attached copy is furnished to the author for internal non-commercial research and education use, including for instruction at the authors institution and sharing with colleagues.

Other uses, including reproduction and distribution, or selling or licensing copies, or posting to personal, institutional or third party websites are prohibited.

In most cases authors are permitted to post their version of the article (e.g. in Word or Tex form) to their personal website or institutional repository. Authors requiring further information regarding Elsevier's archiving and manuscript policies are encouraged to visit:

http://www.elsevier.com/copyright 


\title{
Attributes of researchers and their strategies to recruit minority populations: Results of a national survey
}

\author{
Sandra Crouse Quinn ${ }^{\text {a,* }}$, James Butler III ${ }^{b}$, Craig S. Fryer ${ }^{\text {b }}$, Mary A. Garza ${ }^{\text {b }}$, Kevin H. Kim ${ }^{\text {c }}$, \\ Christopher Ryan ${ }^{\text {d }}$, Stephen B. Thomas ${ }^{\text {e }}$
}

a University of Maryland, School of Public Health, Maryland Center for Health Equity and Department of Family Science, SPH Bldg \#255, College Park, MD 20742 USA

${ }^{\mathrm{b}}$ University of Maryland, School of Public Health, Maryland Center for Health Equity and Department of Behavioral and Community Health, College Park, MD 20742, USA

c Unversity of Pittsburgh, School of Education, Department of Psychology in Education, Pittsburgh, PA 15260, USA

d University of Pittsburgh, School of Medicine, Pittsburgh, PA 12560, USA

e University of Maryland, School of Public Health, Maryland Center for Health Equity and Department of Health Services Administration, College Park, MD 20742, USA

\section{A R T I C L E I N F O}

\section{Article history:}

Received 8 March 2012

Received in revised form 19 June 2012

Accepted 25 June 2012

Available online 5 July 2012

\section{Keywords:}

Recruitment

Strategies

Minority

Research

\begin{abstract}
A B S T R A C T
Despite NIH mandates for inclusion, recruiting minorities is challenging for biomedical and public health researchers. Little is known about how attributes of researchers affect their choice of recruitment strategies. The purpose of this study was to address this gap by examining how use of recruitment strategies relates to other researcher characteristics. To do this, we conducted an online survey from May to August 2010 with researchers (principal investigators, research staff, and IRB members) in which we measured the number and types of recruitment strategies utilized, along with other characteristics of the researchers and their research. We identified two clusters of researchers: comprehensive researchers who utilized a greater number and more diverse and active recruitment strategies, and traditional researchers, who utilized fewer and more passive strategies. Additional characteristics that distinguished the two groups were that comprehensive researchers were more likely than traditional researchers to 1 ) report racial and ethnic differences as one of their specific aims or hypotheses, 2) receive federal (CDC and $\mathrm{NIH}$ ) funding, 3) conduct behavioral or epidemiological research, and 4) have received training in conducting research with and recruiting minorities. Traditional researchers, on the other hand, were more likely to conduct clinical research and a greater (though non-significant) percentage received funding from pharmaceutical sources. This study provides a novel description of how researcher attributes are related to their recruitment strategies and raises a number of future research questions to further examine the implications of this relationship.
\end{abstract}

(C) 2012 Elsevier Inc. All rights reserved.

\section{Introduction}

Recruiting study participants is challenging for clinical, biomedical, and public health researchers, and the recruitment

\footnotetext{
* Corresponding author at: University of Maryland, School of Public Health, 2242CC SPH Building \#255, College Park, MD 20742, USA. Tel.: + 1 301405 8825; fax: +1 3014058397.

E-mail addresses: scquinn@umd.edu (S.C. Quinn), jbutler9@umd.edu (J. Butler), csfryer@umd.edu (C.S. Fryer), magarza@umd.edu (M.A. Garza), khkim@pitt.edu (K.H. Kim), ryancm@upmc.edu (C. Ryan), sbt@umd.edu (S.B. Thomas).
}

of racial and ethnic minorities is especially complex [1,2]. In fact, there is a significant body of literature that documents barriers to minority participation in research [3-6]. Despite these challenges, it is important for researchers to assemble representative samples in order to increase the generalizability of results and contribute to better health outcomes for minorities, which are critical steps in eliminating the persistent health disparities that exist between whites and racial and ethnic minority groups $[7,8]$.

Attention to the recruitment of minorities into research has increased since the NIH's Revitalization Act of 1993, which mandates the inclusion of minorities in federally-sponsored 
research studies, as well as the reporting on and analysis by racial and ethnic groups. Unfortunately, analysis and reporting of results by these groups is lacking [9-11], and minorities continue to be underrepresented in research [12-14], suggesting that challenges to recruiting representative and diverse samples persist.

Understanding and utilizing effective recruitment strategies is one way researchers can ensure inclusive samples, and much attention has focused on determining which strategies are optimal for recruiting minorities into research. Yet a synthesis of the available literature reveals no one strategy is effective for all situations. For example, several studies show indirect, or passive, strategies are the most successful in cases where high proportions of the population are eligible for the study $[5,18,19]$, whereas active strategies, such as in-person appeals, may be most successful when study inclusion criteria are more limited [5,20,21]. Where one study [22] found that a culturally tailored approach was successful in recruiting ethnic minority participants, another found that consumer-centered methods were not more effective for recruiting minorities than traditional methods such as physician referral and media recruitment [23]. Review and other articles propose a variety of "best practices" based on specific situations rather than promoting a single solution [5,15-17]. Thus, researchers are faced with a broad range of strategies from which to choose, and must rely on their experiences, goals, and training to guide them in determining which practice/s to select for a particular study.

Little is known about how researchers' choice of recruiting strategies relates to factors such as their professional background, funding source, research priorities, and training. Yet researchers' attributes may play a role in their recruitment success $[24,25]$. To address this gap, we conducted a survey of researchers (principal investigators, research staff, and IRB members) on their use of different recruitment strategies. We identify two clusters of researchers, comprehensive and traditional, based on the number and types of recruitment strategies they use, and describe how use of these strategies relates to other researcher characteristics. Our study is the first to characterize researchers in this way, and to examine how these strategies differ according to specific researcher attributes. Understanding how researchers' characteristics relate to their choice of recruitment strategies can help us better prepare researchers for recruitment activities that will yield stronger inclusion of minorities in research studies.

\section{Methods}

\subsection{Sample}

The participants were recruited using an email invitation to an online survey. Invitations to participate were sent through the listservs of Public Responsibility in Medicine and Research (PRIM\&R) which includes researchers and IRB members that conduct a wide variety of types of research, Community-Campus Partnerships for Health, numerous clinical and translational science institutes, which include a diversity of researchers, colleagues in academic health centers, and PRIM\&R webinars. Additionally, invitations to participate were included in publications such as the IRB Advisor, and on several Facebook sites, including those for the Centers for Disease Control and
Prevention, the American Public Health Association, and the Journal of Medical Ethics.

\subsection{Measures}

\subsubsection{Recruitment strategies}

The participants were asked if they used the following 17 recruitment strategies in recruiting minorities: a) ethnic/racial focused media, b) targeted mailing/targeted phone calls, c) partnerships with minority organizations, d) partnerships with community based organizations (CBOs), e) partnerships with social service organizations, f) relationships with faith-based organizations, g) tailored recruitment materials, h) matching the ethnicity/race of the recruiter to the population, i) attending social/cultural events, j) research registries, k) community advisory boards, 1) physician referral, $\mathrm{m}$ ) word-of-mouth, $\mathrm{n}$ ) providing financial incentives, o) having a designated recruiter, $\mathrm{p}$ ) conducting research in the field, and q) using community health workers. This list was derived from a review of the literature.

\subsubsection{Funding}

Nine sources of research funding were measured: 1) National Institutes of Health (NIH), 2) Centers for Disease Control and Prevention (CDC), 3) Agency for Health Care Research and Quality (AHRQ), 4) National Science Foundation (NSF), 5) Veterans Administration (VA), 6) Department of Defense (DOD), 7) Foundations, 8) Pharmaceutical Companies, and 9) other. Participants answered yes/no to each funding source, and therefore could select multiple funding sources.

\subsubsection{Types of research}

Participants were asked to select the types of research in which they were involved: 1 ) behavioral and epidemiologic studies, 2) clinical trials, 3) evaluation research, 4) health outcomes research, 5) health services research, 6) intervention research, 7) observational studies, and 8) other. Participants were able to select multiple areas of research that applied to them.

\subsubsection{Recruitment training}

Participants were asked two questions about their previous recruitment training experiences: 1) "Have you received any formal recruitment training?" (yes/no, if yes, please specify), and 2) "Have you received any formal training specific to the recruitment of ethnic and racial minorities?" (yes/no, if yes, please specify).

\subsubsection{Conducting research with minority populations}

We asked participants the following four questions about the involvement of ethnic and racial minorities in their research: 1) the analysis of ethnic/racial differences is a focus of my research (4-point Likert scale ranging from strongly disagree to strongly agree), 2) how often do you report ethnic/racial differences when publishing your research results (4-point Likert scale ranging from never to always), 3) what percentage of your research includes ethnic/racial differences as one of its specific aims or hypotheses, and 4) have you received any specific training or workshops on conducting research with minority populations. 


\subsubsection{Demographics}

These demographic variables were measured: race, ethnicity, gender, age, race, place of work or employment, primary role in research, and years involved with research.

\subsection{Analyses}

The number of clusters was determined by examining both k-mean cluster analysis and two-step cluster analysis [26,27]. For the two-step cluster analysis, Bayesian information criterion (BIC) and the ratio of BIC change were examined. BIC changed by 997.590 from a one cluster to a two cluster solution. BIC only dropped by 208.986 from a two cluster to three cluster solution. Two and three cluster solutions were examined, and the two cluster solution was chosen based on interpretability and its support by the statistics. The cluster group memberships were validated by performing cross-tabulations with funding, type of research, and recruitment training. The chi-square, p-value, and Cramer's V (effect size) are reported. Independent-sample t-tests were performed on continuous dependent variables. Statistical analyses were performed using STATA 11.2, with limited use of SPSS for some of the two-step cluster analysis.

\section{Results}

A total of 347 respondents with a primary or secondary role as a researcher participated in the survey (130 PIs/co-Is, 149 research staff, and 68 IRB members). Throughout this article, we refer to this group as researchers. Sixty one percent (61\%) were Caucasian, 18\% African American, 12\% Latino, and 9\% other. Seventy-nine percent were female and the mean age was 46.8 years ( $S D=11.8$ ). Over $76 \%$ ( 265 of 347 ) completed the survey, which is comparable to completion rates in other online surveys [28,29]. Most importantly, there was no significant difference between participants who completed and did not complete the survey by investigator type (PI/co-I, research staff, IRB), race, or gender. Of the participants who completed the survey, $42.9 \%$ had six or more years receipt of federally-funded grants versus only $25.9 \%$ of participants who did not complete the survey $\left(\chi^{2}(1)=7.50, \mathrm{p}=.006\right.$, Cramer's $\left.\mathrm{V}=.148\right)$. The participants had been involved with research for an average of 14 years $(S D=9.1)$. There was a significant association between race and type of investigator $\left(\chi^{2}(6)=13.16, p=.041\right.$, Cramer's $\mathrm{V}=.139$ ). PIs/co-Is and IRB members were more likely to be white (62\% and 69\%, respectively) than research staff (53\%). Additional demographic information is shown in Table 1.

The k-mean cluster analysis was performed on the 17 strategies for recruiting minorities, coding the strategies as either "used" or "not used". Among 250 participants who completed all 17 items, two clusters were discovered. There were 150 participants (60\%) in cluster 1 and 100 participants $(40 \%)$ in cluster 2 . The cluster groups exhibited significant differences on all strategies except physician referral (Fig. 1). The mean number of strategies used in cluster 1 was 11.7 $(\mathrm{SD}=2.40)$. Members of this group will be referred to as "comprehensive" researchers. We define comprehensive researchers as those who are more likely to utilize a larger number of diverse recruitment strategies. The mean number of strategies used in cluster 2 was $3.7(\mathrm{SD}=2.64)$. Members of this group will be referred to as "traditional" researchers. We define traditional researchers as those who are more likely to
Table 1

Demographic variables by cluster group membership.

\begin{tabular}{|c|c|c|c|c|c|}
\hline & \multicolumn{2}{|l|}{ Cluster groups } & \multirow[t]{2}{*}{$\chi^{2}$} & \multirow[t]{2}{*}{$p$} & \multirow{2}{*}{$\begin{array}{l}\text { Cramer's } \\
\text { V }\end{array}$} \\
\hline & $\begin{array}{l}\text { Comprehensive } \\
(\mathrm{N}=150)\end{array}$ & $\begin{array}{l}\text { Traditional } \\
(\mathrm{N}=100)\end{array}$ & & & \\
\hline Race & & & 10.024 & 0.018 & 0.200 \\
\hline White & $54 \%$ & $66 \%$ & & & \\
\hline $\begin{array}{l}\text { Black/ } \\
\text { African } \\
\text { American }\end{array}$ & $24 \%$ & $10 \%$ & & & \\
\hline Latino & $11 \%$ & $16 \%$ & & & \\
\hline Other & $11 \%$ & $8 \%$ & & & \\
\hline Sex & & & 1.166 & 0.280 & 0.068 \\
\hline Male & $17 \%$ & $23 \%$ & & & \\
\hline Female & $83 \%$ & $77 \%$ & & & \\
\hline Work setting & & & 0.600 & 0.741 & 0.051 \\
\hline University & $64 \%$ & $64 \%$ & & & \\
\hline Hospital & $13 \%$ & $16 \%$ & & & \\
\hline Other & $23 \%$ & $20 \%$ & & & \\
\hline Research role & & & 4.898 & 0.086 & 0.140 \\
\hline PI/Co-I & $41 \%$ & $39 \%$ & & & \\
\hline Staff & $47 \%$ & $38 \%$ & & & \\
\hline \multirow[t]{2}{*}{ IRB } & $13 \%$ & $23 \%$ & & & \\
\hline & & & $\mathrm{t}$ & $\mathrm{p}$ & Cohen's d \\
\hline $\begin{array}{l}\text { Age, mean } \\
\text { (SD) }\end{array}$ & $46.9(11.0)$ & $44.2(12.3)$ & 1.810 & 0.072 & 0.236 \\
\hline $\begin{array}{l}\text { Years } \\
\text { involved } \\
\text { with } \\
\text { research } \\
\text { (SD) }\end{array}$ & $14.6(9.1)$ & $13.7(9.4)$ & 0.073 & 0.466 & 0.095 \\
\hline
\end{tabular}

utilize a smaller set of recruitment strategies. About $55 \%$ of Caucasians were comprehensive researchers compared to $78 \%$ of African Americans and 50\% of Latinos ( $\chi^{2}(3)=10.02, p=$ .02 , Cramer's V =.201.)

We examined the differences between the two clusters by comparing their use of a multitude of research recruitment strategies (Fig. 1). The top five strategies for the comprehensive researchers were 1) partnerships with CBOs (96\% compared to $34 \%$ of traditional);2) attending social and cultural events (89\% compared to $16 \%$ ); 3 ) word of mouth ( $88 \%$ compared to $45 \%$ ); 4) providing financial incentives ( $83 \%$ compared to $41 \%$ ); and 5) tailored recruitment materials (82\% compared to $31 \%$ ). Interestingly, four out of the top five strategies for traditional researchers were the same as for comprehensive researchers, but the proportions of researchers who use those strategies were quite different. The top five strategies for cluster 2 were 1) word of mouth ( $45 \%$ compared to $88 \%$ of comprehensive); 2) providing financial incentives ( $41 \%$ compared to $83 \%$ ); 3) physician referral ( $41 \%$ compared to $48 \%$ ); 4) partnerships with CBOs (34\% compared to $96 \%$ ); and 5) tailored recruitment materials (31\% compared to $82 \%$ ).

Comprehensive researchers were more likely to use a wider array of community engaged strategies including community advisory boards, partnerships with minority organizations, relationships with faith based organizations, conducting research in the field including community sites, using community health workers, and partnerships with social service organizations. Comprehensive researchers were also more likely to use strategies that address racial and ethnic issues 


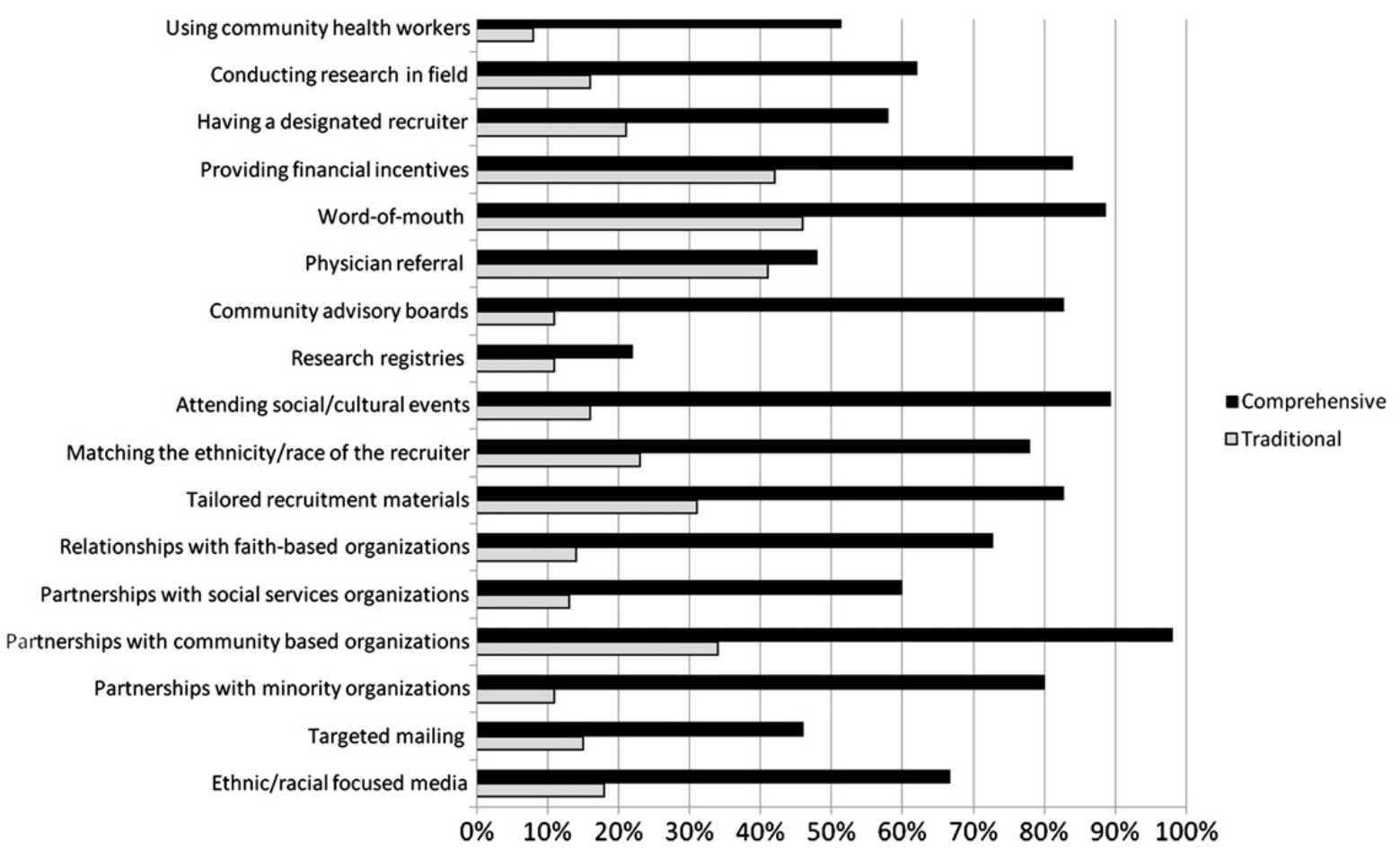

Fig. 1. Use of recruitment strategies. Comparison of comprehensive and traditional researchers' use of the different recruitment strategies. Bars reflect the percent of researchers in each group that use that particular strategy. Differences in percentages were significant for all strategies except for physician referral.

such as matching the race and ethnicity of the researcher to the community and using racial and ethnic media.

In regards to funding source, $31 \%$ of the comprehensive researchers received $\mathrm{CDC}$ funding compared with only $5 \%$ of the traditional researchers $\left(\chi^{2}(1)=25.26, \mathrm{p}<.001\right.$, Cramer's $\mathrm{V}=$ .318). Comprehensive researchers were also more likely than traditional researchers to have received funding from $\mathrm{NIH}$, foundations, and "other" sources, which varied from internal university funding, health department, HRSA, among others (Table 2). Comprehensive researchers were significantly more likely to be involved with behavioral and epidemiologic studies (46\% vs. 30\%) and significantly less likely to be involved with clinical trials (25\% vs. $39 \%$ ) than traditional researchers (Table 3 ).

A greater proportion of those who identified themselves as directly responsible for participant recruitment were comprehensive researchers, as compared to traditional researchers

Table 2

Funding sources for the two cluster groups. Numbers in the "Cluster groups" columns indicate the percentage of researchers in each group who indicated that they receive or have received funding from each source.

\begin{tabular}{|c|c|c|c|c|c|}
\hline \multirow[b]{2}{*}{$\begin{array}{l}\text { Type of } \\
\text { funding }\end{array}$} & \multicolumn{2}{|l|}{ Cluster groups } & \multirow[b]{2}{*}{$\chi^{2}$} & \multirow[b]{2}{*}{$p$} & \multirow[b]{2}{*}{$\begin{array}{l}\text { Cramer's } \\
\text { V }\end{array}$} \\
\hline & Comprehensive & Traditional & & & \\
\hline $\mathrm{NIH}$ & $67 \%$ & $54 \%$ & 4.070 & 0.044 & 0.128 \\
\hline $\mathrm{CDC}$ & $31 \%$ & $5 \%$ & 25.257 & $<.001$ & 0.318 \\
\hline AHRQ & $5 \%$ & $2 \%$ & 1.736 & 0.188 & 0.083 \\
\hline NSF & $3 \%$ & $5 \%$ & 0.434 & 0.510 & 0.042 \\
\hline VA & $7 \%$ & $10 \%$ & 0.906 & 0.341 & 0.060 \\
\hline DOD & $4 \%$ & $6 \%$ & 0.525 & 0.469 & 0.046 \\
\hline Foundation & $38 \%$ & $26 \%$ & 3.896 & 0.048 & 0.125 \\
\hline $\begin{array}{c}\text { Pharmaceutical } \\
\text { companies }\end{array}$ & $15 \%$ & $24 \%$ & 3.481 & 0.062 & 0.118 \\
\hline Other & $36 \%$ & $24 \%$ & 4.025 & 0.045 & 0.127 \\
\hline
\end{tabular}

$\left(\chi^{2}(1)=6.64, \mathrm{p}=.01\right.$, Cramer's $\mathrm{V}=.164,66 \%$ vs. $\left.50 \%\right)$. About $55 \%$ of the comprehensive researchers had received specific training or workshops on conducting research with minority populations compared with only $31 \%$ of the traditional researchers $\left(\chi^{2}(1)=13.50, \mathrm{p}<.001\right.$, Cramer's $\left.\mathrm{V}=.234\right)$. Also, more comprehensive researchers than traditional researchers had received formal recruitment training $\left(\chi^{2}(1)=7.63, p=.006\right.$, Cramer's V $=.175,74 \%$ vs. 55\%) and, additionally, formal training specific to the recruitment of racial and ethnic minorities $\left(\chi^{2}(1)=13.64, \mathrm{p}<.001\right.$, Cramer's $V=.235,81 \%$ vs. $\left.54 \%\right)$.

By and large, comprehensive investigators reported specific interests in racial and ethnic differences in their research. For example, the comprehensive researchers ( $M=52.5 \%, \mathrm{SD}=$ $36.7 \%$ ) were significantly more likely to target minority populations than the traditional researchers $(M=31.1 \%$, $\mathrm{SD}=34.5 \%),{ }^{1} \mathrm{t}(245)=4.593, \mathrm{p}<.001$, Cohen's $\mathrm{d}=.597$. The comprehensive researchers $(M=40.2 \%, S D=37.4 \%)$ were significantly more likely to report racial and ethnic differences as one of their specific aims or hypotheses than the traditional researchers $(M=20.7 \%, S D=30.9 \%)$, $\mathrm{t}(248)=4.31, \mathrm{p}<.001$, Cohen's $\mathrm{d}=.556$. Moreover, the comprehensive researchers $(\mathrm{M}=2.83, \mathrm{SD}=.97)$ were also significantly more likely to perform analysis of racial and ethnic differences as a focus of their research than the traditional researchers $(\mathrm{M}=2.30, \mathrm{SD}=.98), \mathrm{t}(248)=4.25$, $\mathrm{p}<.001$, Cohen's $\mathrm{d}=.549$. The comprehensive researchers $(\mathrm{M}=2.71, \mathrm{SD}=1.19)$ were significantly more likely to report racial and ethnic differences when publishing their

\footnotetext{
1 The data were analyzed using both independent samples t-tests and the Mann-Whitney $U$ test due to the violation of non-normality. Both analyses produced similar results and hence only the parametric results are reported. Mann-Whitney $U$ test results are available upon request.
} 
Table 3

Research types for the two cluster groups. Numbers in the "Cluster groups" columns indicate the percent of researchers in each group who are involved with the different types of research.

\begin{tabular}{|c|c|c|c|c|c|}
\hline \multirow[b]{2}{*}{ Type of research } & \multicolumn{2}{|l|}{ Cluster groups } & \multirow[b]{2}{*}{$\chi^{2}$} & \multirow[b]{2}{*}{$p$} & \multirow[b]{2}{*}{ Cramer's V } \\
\hline & Comprehensive & Traditional & & & \\
\hline Behavioral and epidemiologic studies & $46 \%$ & $30 \%$ & 6.422 & 0.011 & 0.160 \\
\hline Clinical trials & $25 \%$ & $39 \%$ & 5.258 & 0.022 & 0.145 \\
\hline Evaluation research & $19 \%$ & $11 \%$ & 3.100 & 0.078 & 0.111 \\
\hline Health outcomes research & $17 \%$ & $11 \%$ & 1.563 & 0.211 & 0.079 \\
\hline Health services research & $12 \%$ & $16 \%$ & 0.817 & 0.366 & 0.057 \\
\hline Observational studies & $10 \%$ & $16 \%$ & 1.989 & 0.158 & 0.089 \\
\hline Other & $17 \%$ & $17 \%$ & 0.005 & 0.945 & 0.004 \\
\hline
\end{tabular}

research results than the traditional researchers $(\mathrm{M}=2.32$, $\mathrm{SD}=1.39), \mathrm{t}(248)=2.35, \mathrm{p}=.020$, Cohen's $\mathrm{d}=.303$.

\subsection{Limitations}

We acknowledge that this is a convenience sample for which we cannot calculate a response rate or generalize findings to the population of researchers. Additionally, we do not have quantitative data on each investigator's enrollment success. Therefore, we do not make any judgments about the effectiveness or value of one cluster group over the other. However, as attention to the inclusion of minorities in research continues to increase, those researchers who employ a wider array of techniques may feel they are better able to tailor their recruitment efforts to specific minority communities. Furthermore, we believe that this is a promising line of inquiry for a more rigorous examination and that the study presented here, as the first to implicitly link researcher attributes to recruitment strategies, contributes to our understanding of the complexities of the recruitment process and provides some guidance for future research.

The k-mean cluster analysis is limited with respect to finding different types of clusters (i.e. non-spherical shapes or widely different size or density). This limitation is minimized by requesting two clusters and verifying the results with separate cluster algorithms. A second limitation is reproducibility of results since cluster analysis is a data driven technique. However, by examining the distributions of variables and the heterogeneity in the data, the likelihood of finding the relatively low and high clusters is good. There were clear differences between the cluster groups on recruitment strategies used.

\section{Discussion}

In this study we identified two distinct clusters of researchers: comprehensive researchers, who used more recruitment strategies overall and more active recruitment strategies in particular, and traditional researchers, who used fewer and more passive strategies. In addition to these differences, we highlight four characteristics that distinguished the groups: 1 ) their focus on racial and ethnic minorities in their research, 2) funding sources, 3) type of research they conduct, and 4) whether or not they had received any recruitment training. We also consider the implications of these differences for the inclusion of racial and ethnic minorities in research, and highlight several areas where future research is needed to continue to assess the implications of these two cluster groups.

The NIH's Revitalization Act's requirements for research are not limited to simple inclusion of minorities in research, but also include the reporting of samples and analysis of results by racial and ethnic groups. Yet findings from several review articles indicate that many studies fail to report samples sizes by race and ethnicity, and few to none analyze their results by racial or ethnic groups $[9,10,14]$. The focus on racial and ethnic minorities in research is one characteristic that distinguished the comprehensive researchers from the traditional researchers. The comprehensive researchers were more likely to indicate understanding of racial and ethnic differences as one of their specific aims. They were also more likely to perform and report analyses of racial and ethnic differences when publishing their research results. We note that some of the characteristics are related, and are not independent variables (for example, targeting minority populations in research and reporting the results according to racial and ethnic groups), yet the description of all the characteristics associated with each cluster forms an overall picture of the distinctions between the two groups. These reporting results could be explained by our additional finding that comprehensive researchers were more likely to receive funding from the CDC and $\mathrm{NIH}$, and would therefore be required to follow the minority participant inclusion and reporting mandates set forth in the Revitalization Act and subsequent issuances. That said, these results suggest that the comprehensive researchers are better positioned to respond to the overall mandate, not just for inclusion, but able to actually report and conduct analyses by race and ethnicity. Interestingly, while comprehensive researchers were significantly more likely than traditional researchers to receive funding from four sources $(\mathrm{CDC}, \mathrm{NIH}$, foundations, and other (unspecified) sources), in no funding category were traditional researchers significantly more likely than comprehensive researchers to receive funding.

A greater, but non-significant, percentage of traditional researchers did report receiving funding from pharmaceutical companies ( $24 \%$ versus $15 \%, \mathrm{p}=0.062$ ), however. Currently, there is no minority inclusion or reporting requirement for industry sponsored research, such as that financed by pharmaceutical companies. Little is known about the representation of minorities in these studies, though one review found that industry funded studies had lower average minority representation than $\mathrm{NIH}$ funded research (8.1\% industry vs. $16.8 \% \mathrm{NIH}$ ), 
and that a higher (though non-significant) proportion of $\mathrm{NIH}$-sponsored studies reported the ethnic and racial breakdown of their study samples, and reported results according to racial and ethnic analysis [30]. Because pharmaceutical companies rely on FDA approval of their products, should the FDA adopt inclusion mandates, these industry-sponsored research studies may then be required to increase their enrollment of minorities.

A second feature that distinguishes comprehensive from traditional researchers is that comprehensive researchers were more likely to be involved with behavioral and epidemiological research and traditional researchers were more likely to be involved with clinical trials. This breakdown into research types may provide a partial explanation for why comprehensive researchers use greater number overall and more community-based strategies than traditional researchers. The traditional researchers relied primarily on word-of-mouth, financial incentives, and physician referrals, which may be more typical and appropriate strategies to encourage enrollment in clinical research settings, such as physician's offices and hospitals. Inclusion data, however, suggest that they may not be sufficient for adequate accrual, as evidenced by the continued under-representation of minorities in clinical research [12-14]. Therefore, it is very possible that expanding their repertoire of strategies can contribute to better accrual.

On the other hand, because behavioral and epidemiological investigators often conduct their research in more diverse and community-based locations, they may therefore benefit from the use of more and varied strategies to enhance their recruitment efforts. It is important to note, however, that the breakdown into clusters is not simply a split between behavioral/epidemiological researchers and clinical researchers. While the comprehensive researchers were more likely to be behavioral researchers and epidemiologists, and traditional researchers were more likely to be clinicians, $25 \%$ of clinical researchers in our survey fell into the comprehensive cluster group, and $30 \%$ of the behavioral/ epidemiological researchers were in the traditional cluster group. Therefore, the types of strategies are not simply associated with any one research method or design.

A final characteristic that defines comprehensive researchers and traditional researchers is the types of training received. Comprehensive researchers were significantly more likely to have received formal recruitment training, specific training on conducting research with minorities, and formal training specific to the recruitment of minorities. They were also more likely than traditional researchers to be directly responsible for recruitment. It is possible, therefore, that comprehensive researchers use more recruitment strategies because they have learned about them through training and other education efforts. For example, successful engagement with communities through community advisory boards or attending social and cultural events may require a level of effort and comfort for which many are neither prepared nor view as appropriate for their research. Effective engagement with minority communities can be challenging and time-consuming, particularly in communities where researchers are met with suspicion or mistrust. Some of the traditional researchers, who rarely utilize these community based strategies, may refrain not because they are not interested in working with communities, but simply because they do not know how. Study participants, however, have indicated that their decision to participate is influenced by recruiter attributes [25], and researchers may therefore find that their recruitment success can be enhanced through different training programs. Understanding the characteristics of the comprehensive researchers, who are more likely to target the inclusion of minorities in their research, may provide guidance for developing effective training programs, which may also become particularly important for those conducting clinical trials and industry researchers if the FDA moves towards mandating minority inclusion in drug trials. Equally critical is that the extent to which more strategies, as used by comprehensive researchers, will strengthen researchers' abilities to understand racial differences.

\section{Conclusion}

The results from our survey of researchers on strategies used for the recruitment of racial and ethnic minorities indicated there were two distinct groups of researchers, comprehensive and traditional, based on the numbers and types of recruitment strategies used. Additional characteristics typical of each group included the type of research conducted, the emphasis placed on the inclusion of minorities in their research, the types of funding received, and the amount of formal recruitment training received. These results suggest that training in conducting research with minority communities, recruitment, and specifically recruitment of minority participants, can enhance the capacity of researchers to expand their recruitment strategies in number and degree to which they engage communities. We also suggest that the extent to which comprehensive researchers conducted diverse types of research studies bodes well for the adaptation of these strategies in distinct areas of research from more community engaged to more clinical trials studies.

Our results raise a number of future research questions that are important to further understand these factors and implications of these differences. These questions include whether either group is more successful with recruiting minorities into research, whether the effectiveness of different strategies is dependent upon research type (i.e. clinical versus behavioral), and whether training may enhance the ability of traditional researchers to use more community-based strategies.

Future research should also examine the extent to which the utilization of a more diverse array of recruitment strategies by comprehensive researchers positively affects recruitment results and whether comprehensive researchers find that utilizing a diverse array of strategies allows them to successfully tailor their recruitment efforts based on the specifics of their research. While traditional researchers may find that their more limited scope of recruitment strategies are sufficient for their purposes, future work should examine the extent to which these researchers are successful in adequately including minorities in their research. Again, without specific knowledge of research plans or inclusion goals, we cannot make judgments about either group's recruitment success. We do know, however, that the comprehensive researchers focus on minorities in research more often than the traditional researchers, and that this focus is emphasized for researchers receiving federal funding. We stress the need for future investigation into the implications of these two researcher groups, and how the features that distinguish the groups from each other impact 
their effective engagement with and recruitment of racial and ethnic minorities in research.

\section{Acknowledgments}

The study was supported by Award Number RC2MD004766 (Sandra Quinn and Stephen B. Thomas, PIs) from the National Institute on Minority Health and Health Disparities and the Office of the Director, National Institutes of Health. The content is solely the responsibility of the authors and does not necessarily represent the official views of the National Institute on Minority Health and Health Disparities or the National Institutes of Health. James Butler III was supported in part, through his Mentored Career Development Award to Promote Diversity (K01CA134939). Craig S. Fryer was supported in part, through his Mentored Research Scientist Development Award to Promote Diversity (K01CA148789). Mary A. Garza was supported in part, through her Mentored Research Scientist Development Award to Promote Diversity (K01CA140358). The funding agencies had no role in the study design, analysis or interpretation of the data, writing of the report, or in the decision to submit the article for publication. We give thanks to David Barnard for his participation in discussions of the results, and to Erica Casper for her editorial assistance.

\section{References}

[1] Galea S, Tracy M. Participation rates in epidemiologic studies. Ann Epidemiol 2007;17:643-53.

[2] Sullivan-Bolyai S, Bova C, Deatrick JA, Knafl K, Grey M, Leung K, et al. Barriers and strategies for recruiting study participants in clinical settings. West J Nurs Res 2007;29:486-500.

[3] Spears CR, Nolan BV, O'Neill JL, Arcury TA, Grzywacz JG, Feldman SR. Recruiting underserved populations to dermatologic research: a systematic review. Int J Dermatol 2011;50:385-95.

[4] Rajakumar K, Thomas SB, Musa D, Almario D, Garza MA. Racial differences in parents' distrust of medicine and research. Arch Pediatr Adolesc Med 2009;163:108-14.

[5] Yancey AK, Ortega AN, Kumanyika SK. Effective recruitment and retention of minority research participants. Annu Rev Public Health 2006;27:1-28.

[6] Peters-Lawrence MH, Bell MC, Hsu LL, Osunkwo I, Seaman P, Blackwood $\mathrm{M}$, et al. Clinical trial implementation and recruitment: lessons learned from the early closure of a randomized clinical trial. Contemp Clin Trials 2012;33:291-7.

[7] Blackman DJ, Masi CM. Racial and ethnic disparities in breast cancer mortality: are we doing enough to address the root causes? J Clin Oncol 2006;24:2170-8.

[8] Pleis JR, Ward BW, Lucas JW. Summary health statistics for U.S. adults: National Health Interview Survey, 2009. In: Statistics NCfH, editor.2010, p. 217.

[9] Corbie-Smith G, St George DM, Moody-Ayers S, Ransohoff DF. Adequacy of reporting race/ethnicity in clinical trials in areas of health disparities. J Clin Epidemiol 2003;56:416-20.

[10] Geller SE, Koch A, Pellettieri B, Carnes M. Inclusion, analysis, and reporting of sex and race/ethnicity in clinical trials: have we made progress? J Womens Health (Larchmt) 2011;20:315-20.
[11] Frampton GK, Shepherd J, Dorne JL. Demographic data in asthma clinical trials: a systematic review with implications for generalizing trial findings and tackling health disparities. Soc Sci Med 2009;69:1147-54.

[12] Murthy VH, Krumholz HM, Gross CP. Participation in cancer clinical trials. JAMA 2004;291:2720-6.

[13] Wendler D, Kington R, Madans J, Van Wye G, Christ-Schmidt H, Pratt LA, et al. Are racial and ethnic minorities less willing to participate in health research? PLoS Med 2006;3:201-10.

[14] Sullivan PS, McNaghten AD, Begley E, Hutchinson A, Cargill VA. Enrollment of racial/ethnic minorities and women with HIV in clinical research studies of HIV medicines. J Natl Med Assoc 2007;99:242-50.

[15] Carroll J, Yancey A, Spring B, Figueroa-Moseley C, Mohr D, Mustian K, et al. What are successful recruitment and retention strategies for underserved populations? Examining physical activity interventions in primary care and community settings. Transl Behav Med 2011;1:234-51.

[16] UyBico SJ, Pavel S, Gross CP. Recruiting vulnerable populations into research: a systematic review of recruitment interventions. J Gen Intern Med 2007;22:852-63.

[17] Nicholson LM, Schwirian PM, Klein EG, Skybo T, Murray-Johnson L, Eneli I, et al. Recruitment and retention strategies in longitudinal clinical studies with low-income populations. Contemp Clin Trials 2011;32:353-62.

[18] Fouad MN, Corbie-Smith G, Curb D, Howard BV, Mouton C, Simon M, et al. Special populations recruitment for the Women's Health Initiative: successes and limitations. Control Clin Trials 2004;25:335-52.

[19] Appel LJ, Vollmer WM, Obarzanek E, Aicher KM, Conlin PR, Kennedy $\mathrm{BM}$, et al. Recruitment and baseline characteristics of participants in the Dietary Approaches to Stop Hypertension trial. DASH Collaborative Research Group. J Am Diet Assoc 1999;99:S69-75.

[20] Royal C, Baffoe-Bonnie A, Kittles R, Powell I, Bennett J, Hoke G, et al. Recruitment experience in the first phase of the African American Hereditary Prostate Cancer (AAHPC) study. Ann Epidemiol 2000;10: S68-77.

[21] Gilliss CL, Lee KA, Gutierrez Y, Taylor D, Beyene Y, Neuhaus J, et al. Recruitment and retention of healthy minority women into communitybased longitudinal research. J Womens Health Gend Based Med 2001;10: $77-85$.

[22] MacEntee MI, Wyatt C, Kiyak HA, Hujoel PP, Persson RE, Persson GR, et al. Response to direct and indirect recruitment for a randomised dental clinical trial in a multicultural population of elders. Community Dent Oral Epidemiol 2002;30:377-81.

[23] Arean PA, Alvidrez J, Nery R, Estes C, Linkins K. Recruitment and retention of older minorities in mental health services research. Gerontologist 2003;43:36-44.

[24] Williams IC, Corbie-Smith G. Investigator beliefs and reported success in recruiting minority participants. Contemp Clin Trials 2006;27:580-6.

[25] Felsen CB, Shaw EK, Ferrante JM, Lacroix LJ, Crabtree BF. Strategies for in-person recruitment: lessons learned from a New Jersey primary care research network (NJPCRN) study. J Am Board Fam Med 2010;23: 523-33.

[26] Zhang T, Ramakrishnan R, Livny M. BIRCH: an efficient data clustering method for very large databases. SIGMOD Rec 1996;25:103-14.

[27] Chiu T, Fang D, Chen J, Wang Y, Jeris C. A robust and scalable clustering algorithm for mixed type attributes in large database environment. Proceedings of the seventh ACM SIGKDD international conference on Knowledge discovery and data mining. San Francisco, California: ACM; 2001. p. 263-8.

[28] Fricker S, Galesic M, Tourangeau R, Yan T. An experimental comparison of web and telephone surveys. Public Opin Q 2005;69:370-92.

[29] Galesic M, Bosnjak M. Effects of questionnaire length on participation and indicators of response quality in a web survey. Public Opin Q 2009;73: $349-60$.

[30] Dickerson DL, Leeman RF, Mazure CM, O'Malley SS. The inclusion of women and minorities in smoking cessation clinical trials: a systematic review. Am J Addict 2009;18:21-8. 